\title{
Evidence for weapon-related traumas in medieval Japan: observations of the human crania from Seiyokan
}

\author{
Tomohito NAGAOKA ${ }^{1 *}$, Kazuhiro UzAwA ${ }^{2}$, Kazuaki HiRATA ${ }^{1}$ \\ ${ }^{1}$ Department of Anatomy, St. Marianna University School of Medicine, Kawasaki 216-8511, Japan \\ ${ }^{2}$ Faculty of Human Sciences, University of East Asia, Shimonoseki 751-8503, Japan
}

Received 7 October 2009; accepted 23 December 2009

\begin{abstract}
The Seiyokan site is located in Kamakura, Japan, and has yielded 91 human skeletons belonging to the 14-15th centuries AD. The purposes of this study are to examine the human crania from the archeological site at Seiyokan, to analyze the presence, distribution, and variability of their weaponrelated traumas, and finally to better understand violence in medieval Japan from osteological evidence. The results demonstrate that the traumas on the crania have morphological features consistent with human-induced cut marks. The presence of cut marks on the Seiyokan crania, which strongly suggests the prevalence of violence in medieval Japan, is in accord with the historical background - that a militarily organized society was founded by force and that the rise to political power of the warrior class and the establishment of a military government resulted in continuous disturbances, armed conflicts, and violent death.
\end{abstract}

Key words: weapon-related traumas, scanning electron microscope, human skeletons, Kamakura, medieval period

\section{Introduction}

Weapon-related traumas on human skeletons have been documented in a wide range of societies both in prehistoric and historic periods (e.g. Andrushko et al., 2005; Buzon and Richman, 2007; Finucane, 2008; Murphy et al., 2002; Tung, 2007). Scientists have examined the weapon-related traumas of human skeletons as direct and objective evidence of violence in archeological and forensic contexts (e.g. Boylston, 2000; Larsen, 1997; Walker, 2001; Williamson et al., 2003). Osteoarcheological studies of weapon-related traumas on human skeletons have shed new light on violence in earlier societies.

\section{Weapon-Related Traumas in Medieval Japan}

The medieval period of Japan spans nearly 400 years from the late 12th century $\mathrm{AD}$ to the end of the 16th century AD. It is characterized by the beginning of feudal society governed by warriors, or samurai, after the Genpei conflict of $1180-1185$, a civil war involving two great warrior clans, Minamoto and Taira. The first military government, the Kamakura Shogunate (1192-1333), was established in Kamakura by Minamoto Yoritomo (Figure 1). This was the first in a continuous succession of military regimes that

\footnotetext{
* Correspondence to: Tomohito Nagaoka, Department of Anatomy, St. Marianna University School of Medicine, 2-16-1 Sugao, Miyamae Ward, Kawasaki 216-8511, Japan.

E-mail: nagaoka@marianna-u.ac.jp

Published online 10 March 2010

in J-STAGE (www.jstage.jst.go.jp) DOI: 10.1537/ase.091007
}

dominated Japan until the 19th century. In 1333, the Kamakura Shogunate was overthrown by Nitta Yoshisada, and was replaced by the second military government, the Muromachi Shogunate (1338-1573), which was founded in Kyoto by Ashikaga Takauji.

The rise to political power of the warrior class and the establishment of a military government resulted in continuous disturbances, armed conflicts, and violent death, including non-warrior classes. It is clear that weapon-related traumas and mutilations increased with the beginning of feudal society, compared with the preceding Heian period, which is considered the peak of the Japanese imperial court (Suzuki, 1956, 1989; Morimoto, 1987; Morimoto and Hirata, 1992; Hirata et al., 2004; Hirata and Nagaoka, 2005; Nagaoka et al., 2009). In Kamakura City, which was the capital of the first Shogunate, a considerable number of medieval human skeletons have been unearthed over the past 50 years. Many scientists have studied these skeletal remains and demonstrated that a large number of these skeletons bear lesions related to violent acts. Suzuki (1956) examined medieval Japanese skeletons from the Zaimokuza site, Kamakura, and reported cases of cut marks caused by a sharp-edged weapon. Obvious cut marks were found on 33 crania out of 283 individuals (11.7\%), but when scratches are included, the frequency is $65.7 \%(186 / 283)$. He thought that the conditions in which the skeletal remains were buried were due to the battle which ensued when Nitta attacked Kamakura in 1333. Morimoto (1987) examined two male skulls and the upper cervical vertebrae from the Imakoji-nishi site, Kamakura, and found sword cuts in the cervical vertebrae, giving evidence of decapitation by sword. Morimoto and Hirata (1992) reported an additional decapitated male skull 
a
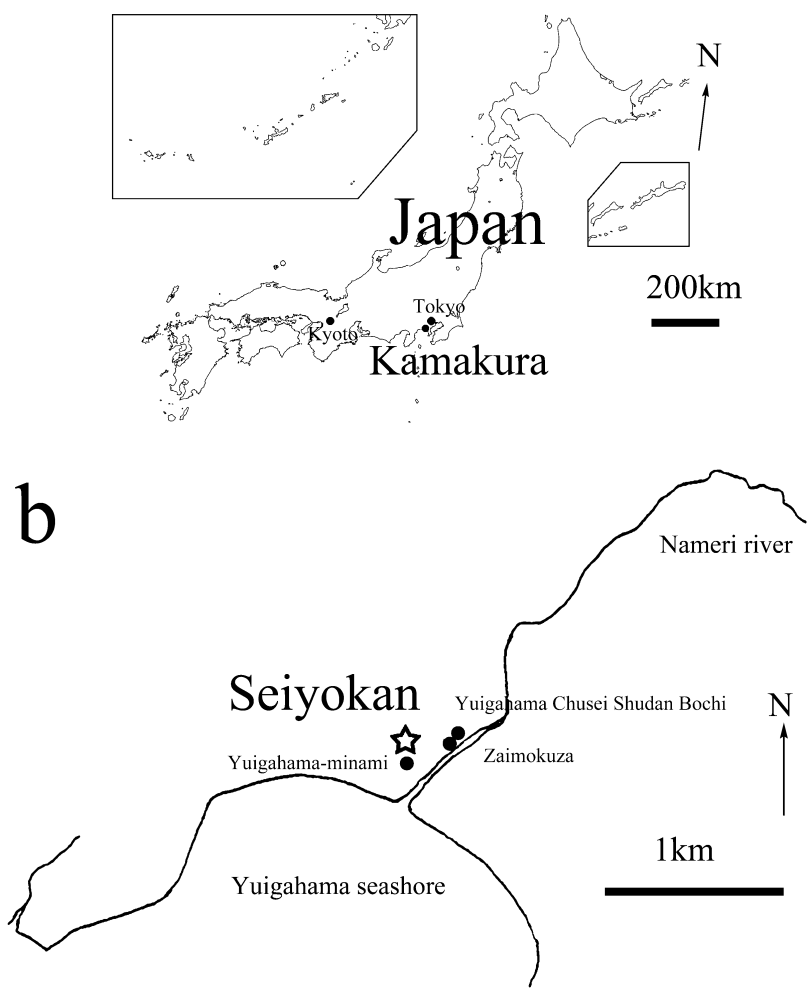

Figure 1. (a) Map of Japan showing the location of Kamakura City in which the Seiyokan site is located. (b) Map of Kamakura City showing the location of the Seiyokan site.

and upper cervical vertebrae from the Yuigahama Chusei Shudan Bochi site (No. D197), Kamakura. Hirata et al. (2004) described the cut marks of skeletons from the archeological sites at Seiyokan, Yuigahama-minami, and Yuigahama Chusei Shudan Bochi (No. 372) in Kamakura, and suggested that these people were killed by warfare. Nagaoka et al. (2009) conducted a thorough observation of weapon-related traumas of Yuigahama Chusei Shudan Bochi (No. 372) using a scanning electron microscope, and concluded that the traumas on the crania have morphological features consistent with human-induced cut marks, and that the microscopic approach provides important information for identifying anthropogenic cut marks on human skeletal remains.

Although several reports on traumas have been published, the osteological evidence for weapon-related traumas is often anecdotal and diagnosis is subject to the observer's experience. Peri-mortem traumatic lesions without the formation of new bone callus are often difficult to distinguish from post-mortem damage caused by site-formation processes or post-recovery damage from excavation and curation (Walker, 2001), and the patterns of cut marks vary according to social context (Boylston, 2000). The study of weapon-related traumas, therefore, requires standards to distinguish human-induced traumas and their populationspecific interpretation. The purposes of this study are to describe the macroscopic and microscopic morphology of cut marks observed on human skeletons from the archeological site of Seiyokan in medieval Japan, to examine their presence, distribution, and variability, and finally to better understand violence in medieval Japan from osteological evidence.

\section{Materials}

The materials used here were seven injured crania from the Seiyokan site $\left(35^{\circ} 18^{\prime} 37^{\prime \prime} \mathrm{N}, 139^{\circ} 32^{\prime} 40^{\prime \prime} \mathrm{E}\right)$, which is located along the Yuigahama seashore of the southern end of Kamakura City in Japan (Figure 1). It is adjacent to the medieval sites of Zaimokuza (Suzuki, 1956), Yuigahamaminami (i.e. YM, medieval cemetery in the southern end of the Yuigahama area) (Hirata et al., 2002), and Yuigahama Chusei Shudan Bochi (No. 372) (i.e. YCSB, multiple cemetery of the medieval period in the Yuigahama area) (Hirata and Nagaoka, 2005; Nagaoka et al., 2009) in Kamakura. A survey of the Seiyokan site was undertaken in 1982 by the Kamakura Board of Education, and yielded 91 human skeletal remains belonging to the 14 th-15th centuries AD (pottery typology; Tashiro and Tamabayashi, 1984). The ratio of adults to subadults is $9: 1$ and the ratio of adult males to adult females is $1: 1$ (Hirata et al., 2004). Fifty-five crania were excavated from a mass grave and were not associated with mandibles, cervical vertebrae, or other postcranial bones (Morimoto et al., 1984). There are indications that they were secondarily buried after the decay of soft tissues. The remaining 36 individuals were composed of entire parts of skeletons from single or multiple graves (Morimoto et al., 1984). The use of crania in this study has two advantages: first, the preservation states of skeletal remains vary among archeological sites; secondly, in Seiyokan, cut marks were observed on crania alone. The materials are kept at the Department of Anatomy, St. Marianna University School of Medicine (Kawasaki, Japan).

The comparative samples were human remains from three archeological sites: the Zaimokuza site, which is composed mostly of mass cranial graves (Suzuki, 1956); the YM site, composed of single or multiple graves that contain entire skeletons (Hirata et al., 2002), and the YCSB site, composed of both burial types (Hirata and Nagaoka, 2005; Nagaoka et al., 2009). A brief description of the YM and YCSB crania with sharp-force traumas is given in Appendix 1.

\section{Methods}

\section{Sex determination and age-at-death estimation}

Sex determination for adult individuals was carried out on the basis of macroscopic assessment of the pelvic features, such as preauricular surface, greater sciatic notch, preauricular sulcus, composite arch, inferior pelvis (Bruzek, 2002), ventral arc, subpubic concavity, and the medial aspect of the ischiopubic ramus (Phenice, 1969). The individuals lacking pelvic bones were sexually determined by cranial features that include the supraorbital ridge, frontal tuberosity, mastoid process, and exterior occipital prominence (White and Folkens, 2000; Nagaoka et al., 2008).

In order to estimate the age at death for adult individuals, chronological metamorphosis of the pubic symphysis (Todd, $1920,1921)$, and that of the auricular surface of the ilium 
(Lovejoy et al., 1985; Buckberry and Chamberlain, 2002) were used. The individuals lacking pelvic bones were assessed by dental formation and eruption (Ubelaker, 1989), cranial suture closure (Okada, 1961), and occipital synchondrosis closure (Wakebe, 1990).

\section{Identification of cut marks}

This study identified cut marks produced by sharp-edged weapons based on the macroscopic criteria of Walker and Long (1977), Boylston (2000), and Lewis (2008). Unhealed cut marks produced by a sharp-edged weapon are characterized by "a linearity," "a well-defined clean edge," "a flat, smooth, polished cut surface" (Boylston, 2000: 361), and a V-shaped cross section (Walker and Long, 1977). Furthermore, macroscopic profiles for cut marks made by steel knives and swords are different: knives always produce $\mathrm{V}$ shaped profiles in cross-section without flaking of the cut mark walls, while Japanese swords produce cut marks that yield a unilateral flaking of the cut mark walls and exhibit a long, narrow, and elliptical shape from a superior view (Lewis, 2008).

During our analysis of the Seiyokan sample, humaninduced cut marks on six crania were clearly identified, while one indeterminable case was also recognized. In this paper, we further examined the cut marks using a scanning electron microscope (SEM) by the criteria of Shipman (1981), Shipman and Rose (1983), and Shipman et al. (1984). Microscopic appearance is one of the most useful diagnostic characteristics in identifying cut marks on archeological bones. Shipman and her colleagues suggested the diagnostic key to the microscopic features distinguishing cut marks from marks caused by various taphonomic events (Shipman, 1981; Shipman and Rose, 1983; Shipman et al., 1984). Cut marks made by either steel or stone knives tend to be V-shaped in cross-section, and those produced by stone tools usually show many fine striations along with the main grooves, depending on the morphology of the edge of the artifact used (Shipman, 1981; Shipman and Rose, 1983; Shipman et al., 1984). The morphological difference between steel tools and stone tools is that the former have steep and smooth V-shaped profiles, while the latter have multiple striations within a groove (Greenfield, 1999).

SEM observation provides images of superior resolution and depth of field, and allows us to avoid intuitive evaluation of the cut marks (Shipman, 1981). To observe cut marks by a SEM, we used replicas instead of original materials for several reasons. First, a SEM chamber is too small to hold the original materials (Rose, 1983). Second, the use of replicas prevents breakage of the original (Rose, 1983). The other advantages of replicas that Rose (1983) has pointed out are the availability in field or outside-lab settings, easy transportation, application to porous bones or teeth, etc. The procedures for making replicas and observing them by a SEM have been described previously (Nagaoka et al., 2009).

\section{Description of cut marks caused by a sharp-edged weapon \\ Cut mark types}

For comparisons with previous studies carried out on the medieval Kamakura samples, unhealed cut marks by sharp- edged weapons were classified into gashes, incisions, and scratches according to the systems of Suzuki (1956). Determinations of these marks and equivalences to other nomenclature applied by other investigators are as follows. (1) Gashes are traumas that penetrate both the external and internal laminae of the skull (Figure $2 \mathrm{a}-\mathrm{c}$ ). These marks are broad and $\mathrm{V}$-shaped in cross section and were most probably produced by a sword striking a bone surface with a blow (dynamic loading) (Shipman, 1981; Cook, 1986). The same sorts of marks have also been termed "chop marks" or "hack marks" by various authors and these nomenclatures are more common than "gash" (cf. White, 1992: 148). In this study, however, we follow Suzuki's terminology which describes only the topography of the marks. In battles between warriers, the Japanese sword was swung at a high speed, describing an arc. When the cutting edge penetrated the soft tissue and reached the bone, it caused hacking damage on the contact area followed by a slicing motion of the edge. Therefore, chopping and slicing actions occur consecutively in a single blow of the sword. This characteristic handling of the cutting artifacts may cause bone modification which shows both dynamic and static loading of the cutting tools. Accordingly we classify cut marks in terms of their depth as well as their outline morphology in order to determine their cause more closely. (2) Incisions are typically sharp grooves produced by moving an artifact (static loading) across a bone surface along the long axis of the edge. In this study, only those traumas that penetrated the external but not internal lamina of the skull were classified in this category (Figure 2d). (3) Scratches are groups of shallow and short cuts, most of which are parallel ones caused by the sliding motion of a sword applied to the skull (Figure 2e). This category contains two types of subcategories produced by two different procedures. One is a group of short cut marks distributed over a relatively small area on the bone surface that was caused by multiple applications of slicing behavior. The other is "scrape marks" which are produced by drawing an artifact across a bone surface in a direction roughly perpendicular to the long axis of the edge (Shipman, 1981). These marks are attributed to periosteum removal (Binford, 1981).

When the number of individuals with each kind of cut mark was recorded, an individual with two or three types of cut marks was separately counted according to each cut mark type.

\section{Location}

The location of cut marks was also recorded. As White (1992) pointed out, in a cluster of roughly parallel marks, deciding exactly which mark to count becomes arbitrary. Following White's procedure, we recorded the number of cut marks by estimating the number of strokes that caused each cut mark cluster. Therefore, a cut mark or a scratch that continued over more than one bone element was counted as one. When the number of cut marks on each bone was recorded, a continuous cut mark on two bones or more was separately counted according to bone.

\section{Statistical analysis}

Statistical analysis was conducted by the statistical package R2.2.1 (R Development Core Team, 2005). 
a

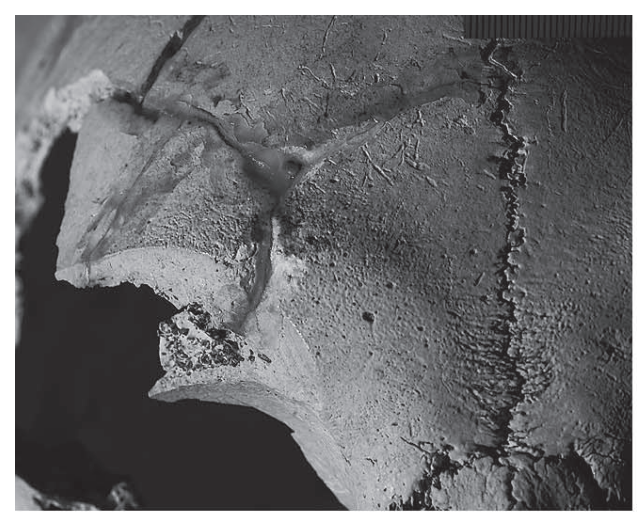

C

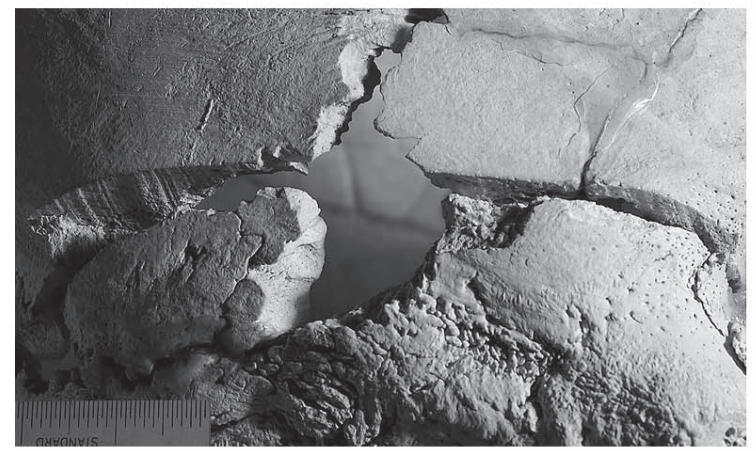

e

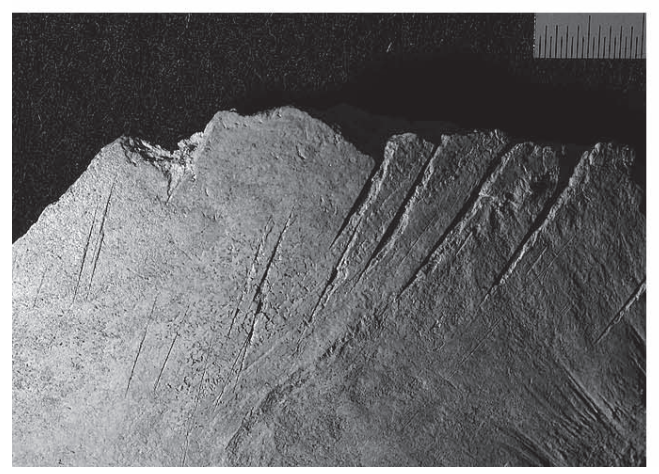

b

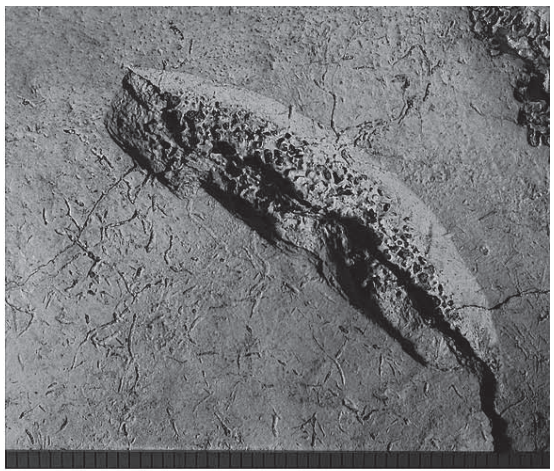

d

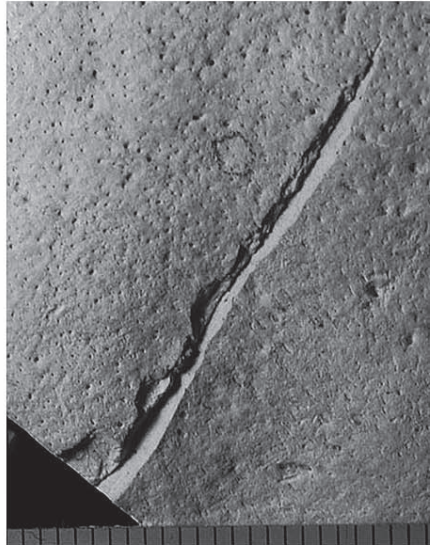

Figure 2. Cut mark types. (a) Anterior view of the gash on the frontal bone (specimen no. 1-1, Seiyokan). (b) Lateral view of the gash on the right parietal bone (specimen no. 1-13, Seiyokan). (c) Lateral view of the gash on the right parietal and occipital bones (specimen no. 1-9, Seiyokan). (d) Posterior view of the incision on the occipital bone (specimen no. 1-9, Seiyokan). (e) Lateral view of the scratches on the left parietal bone (specimen no. 42-6, Yuigahama Chusei Shudan Bochi).

\section{Results and Discussion}

\section{Weapon-related traumas in Seiyokan}

The weapon-related traumas detected in the Seiyokan sample were limited to sharp-force traumas. Since we did not find any signs of blunt or projectile traumas, we focused on the examination of cut marks made by an edged weapon.

The sharp-force traumas were identified on six crania (specimen nos. 1, 1-1, 1-8, 1-9, 1-13, 1-31) (Table 1), and there is one individual with an indeterminable case of cut marks (specimen no. W-1). When the indeterminable case is excluded, cut marks were found on three adult males and one adult female out of the six individuals, but not in subadults (Table 1). The frequency of individuals with cut marks is $6.6 \%$ out of 91 individuals.

The six individuals with cut marks were all excavated from the mass cranial grave. The frequency of individuals with cut marks is $10.9 \%$ out of 55 individuals. On the other 


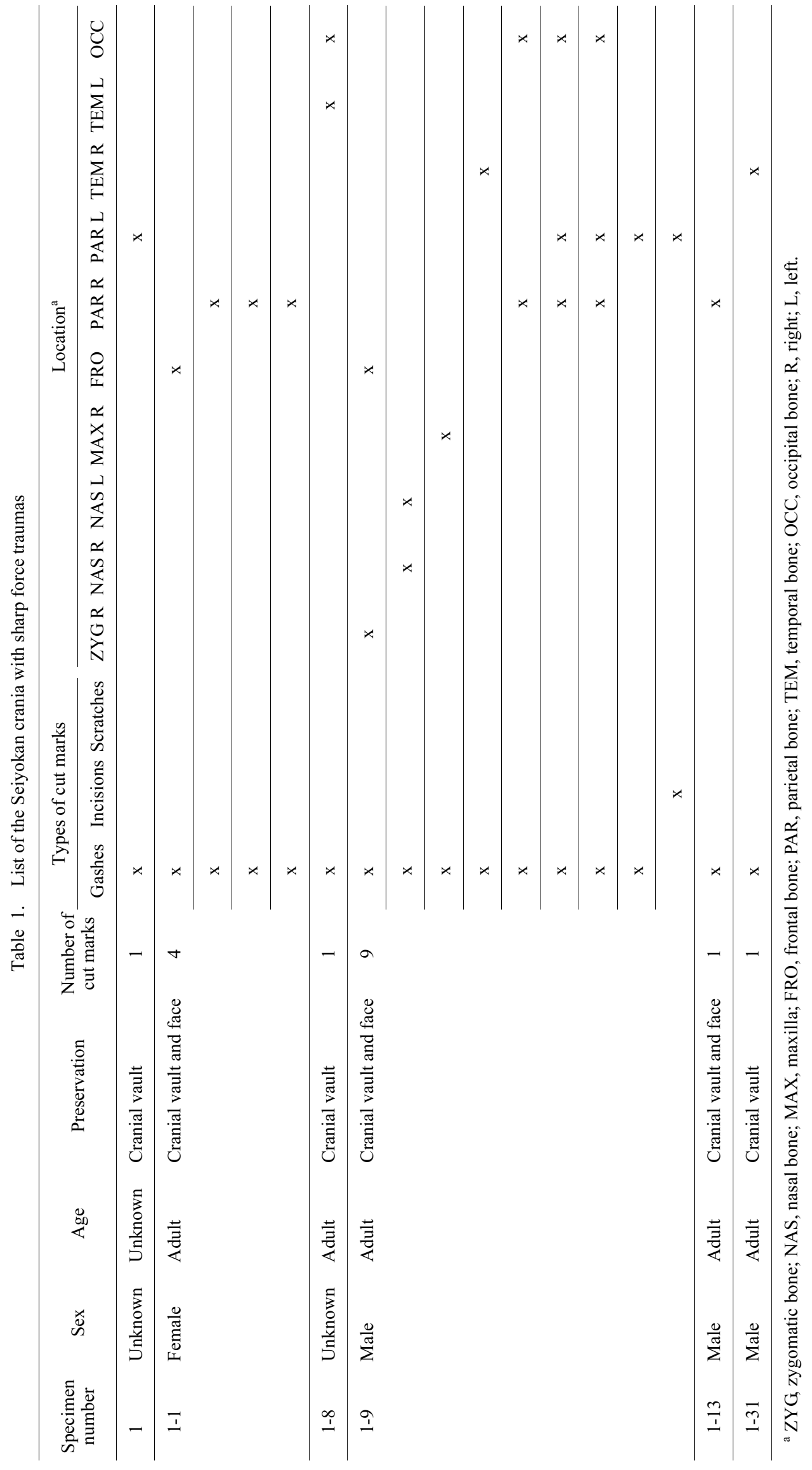


hand, there are no cut marks on 36 crania from the single or multiple graves containing entire skeletons. More traumas tend to occur in the former burial category than in the latter, although the frequencies are not statistically significant (Fisher's exact test, $P=0.081$ ).

The number of cut marks on the six individuals is 17 (Table 1, Table 3 ). They are all characterized by a linear, flat, clearly edged, and polished cut surface, which are consistent with the features of cut marks made by sharp steel blades (Figure 2a-d) (Boylston, 2000; Lewis, 2008). One is an incision which is restricted to the outer table and is characterized by a polished cut surface $(5.9 \%$ out of 17 cut marks), whereas 16 are gashes which penetrate to both the external and internal laminae (94.1\% out of 17 ). The former produces a unilateral flaking of cut marked surfaces and exhibits an asymmetrically elliptical shape from a superior view (Figure 2d). The latter, on the other hand, often enter into the cranial cavity, which is indicative of lethal trauma (Figure $2 \mathrm{a}-\mathrm{c}$ ). Neither the incision nor the gashes exhibit a color difference between the walls of the grooves and the original bone surfaces. The absence of healing traits from the injuries indicates that they were cut either immediately prior to death or in the post-mortem period. Although the cut marks appear predominantly on the parietal bones, the Seiyokan samples exhibit injuries not only on the frontal, parietal, temporal, and occipital bones but also on the zygomatic, nasal, and maxillary bones (Table 1, Table 4).

\section{Comparison of cut marks between the Seiyokan samples and other archeological sites}

Frequency

The frequency of unhealed cut marks exhibit wide variability among the four archeological sites (Table 2). When the indeterminable case is excluded, the frequency of unhealed cut marks in the Seiyokan samples is $6.6 \%$ out of 91 individuals. This is significantly higher than that of YCSB $(1.4 \%)$ (Fisher's exact test, $P=0.007)$ and YM (0.6\%) (Fisher's exact test, $P<0.001$ ), but lower than that of Zaimokuza (65.7\%) (Fisher's exact test, $P<0.001$ ).

\section{Burial types}

The relationship between cut mark frequency and burial types was examined (Table 2). In Seiyokan, more traumas were observed in the mass cranial grave $(10.9 \%)$ than in the

Table 2. Comparison of cut mark frequency and burial types

\begin{tabular}{|c|c|c|c|c|c|}
\hline \multicolumn{2}{|l|}{ Burial type } & Seiyokan & $\mathrm{YCSB}^{\mathrm{a}}$ & $\mathrm{YM}^{\mathrm{b}}$ & Zaimokuza $^{\mathrm{c}}$ \\
\hline \multirow[t]{3}{*}{ Mass cranial grave } & Number of individuals & 55 & 380 & & 283 \\
\hline & Number of individuals with cut marks & 6 & 8 & & 186 \\
\hline & Frequency $(\%)$ & 10.91 & 2.11 & & 65.70 \\
\hline \multirow{3}{*}{$\begin{array}{l}\text { Single and multiple graves that } \\
\text { contain entire skeletons }\end{array}$} & Number of individuals & 36 & 212 & 667 & \\
\hline & Number of individuals with cut marks & 0 & 0 & 4 & \\
\hline & Frequency $(\%)$ & 0.00 & 0.00 & 0.60 & \\
\hline \multirow[t]{3}{*}{ Total } & Number of individuals & 91 & 592 & 667 & 283 \\
\hline & Number of individuals with cut marks & 6 & 8 & 4 & 186 \\
\hline & Frequency $(\%)$ & 6.59 & 1.35 & 0.60 & 65.70 \\
\hline
\end{tabular}

${ }^{\text {a }}$ Nagaoka et al. (2009).

${ }^{\mathrm{b}}$ Hirata et al. (2002, 2004).

c Suzuki (1956), Hirata et al. (2004).

Table 3. Comparison of cut mark types among four archaeological sites

\begin{tabular}{|c|c|c|c|c|c|c|}
\hline \multirow{2}{*}{ Archaeological sites $^{\mathrm{a}}$} & \multicolumn{3}{|c|}{ Number of cut marks } & \multicolumn{3}{|c|}{ Number of individuals with cut marks } \\
\hline & Gashes & Incisions & Scratches & Gashes & Incisions & Scratches \\
\hline Seiyokan & 16 & 1 & 0 & $6^{\mathrm{b}}$ & $1^{\mathrm{b}}$ & 0 \\
\hline $\mathrm{YCSB}^{\mathrm{c}}$ & 9 & 2 & 3 & $6^{\mathrm{b}}$ & $2^{b}$ & $3^{\mathrm{b}}$ \\
\hline$Y^{\mathrm{d}}$ & 8 & 5 & 0 & $3^{\mathrm{b}}$ & $2^{\mathrm{b}}$ & 0 \\
\hline Zaimokuza $^{\mathrm{e}}$ & 9 & 94 & l & 5 & 28 & 153 \\
\hline \multirow{2}{*}{ Archaeological sites $^{\mathrm{a}}$} & \multicolumn{3}{|c|}{ Frequency $(\%)$} & \multicolumn{3}{|c|}{ Frequency $(\%)$} \\
\hline & Gashes & Incisions & Scratches & Gashes & Incisions & Scratches \\
\hline Seiyokan & 94.12 & 5.88 & 0.00 & 85.71 & 14.29 & 0.00 \\
\hline $\mathrm{YCSB}^{\mathrm{c}}$ & 64.29 & 14.29 & 21.43 & 54.55 & 18.18 & 27.27 \\
\hline$Y^{\mathrm{d}}$ & 61.54 & 38.46 & 0.00 & 60.00 & 40.00 & 0.00 \\
\hline Zaimokuza $^{\mathrm{e}}$ & / & / & / & 2.70 & 15.10 & 82.20 \\
\hline
\end{tabular}

${ }^{a}$ YCSB, Yuigahama Chusei Shudan Bochi; YM, Yuigahama-minami.

${ }^{\mathrm{b}}$ When the number of individuals with each kind of cut mark type was recorded, an individual with two or three types was counted separately according to each cut mark type.

${ }^{\mathrm{c}}$ Nagaoka et al. (2009).

${ }^{\mathrm{d}}$ Hirata et al. (2002, 2004).

e Suzuki (1956), Hirata et al. (2004). 
single graves or simultaneous burials containing entire skeletons $(0 \%)$, but there is no statistical significance (Fisher's exact test, $P=0.081)$. The YCSB frequency of the former $(2.1 \%)$ versus the latter $(0 \%)$ suggests a similar tendency, but both are again insignificant (Fisher's exact test, $P=0.056)$. The frequency of Zaimokuza $(65.7 \%)$ versus YM $(0.6 \%)$, which respectively represent the former and the latter, strengthens the argument that traumas were possibly concentrated in the mass cranial grave. The mass grave containing a considerable number of crania without mandibles, cervical vertebrae, and other postcranial bones indicates that they were secondarily buried after the decay of soft tissues, and thus may illustrate unusual situations of death.

\section{Cut mark types and location}

Table 3 shows the frequency of the three types of cut marks in Seiyokan, YCSB, YM, and Zaimokuza. In terms of the number of cut marks, the frequency of gashes was the highest in Seiyokan (94.1\%), while the remaining populations show much lower percentages. However, there are no statistical differences between Seiyokan and YCSB (Fisher's exact test, $P=0.101$ ) or between Seiyokan and YM (Fisher's exact test, $P=0.169$ ).

The number of individuals with three cut mark types was further compared. The comparison suggested that the frequency of individuals with gashes was again the highest in Seiyokan $(85.7 \%)$. Although there are no statistical differ- ences between Seiyokan and YCSB (Fisher's exact test, $P=0.496$ ) or between Seiyokan and YM (Fisher's exact test, $P=0.523$ ), a comparison between Seiyokan and Zaimokuza shows a clear contrast (Fisher's exact test, $P<0.001)$. In Zaimokuza, most of the cranial traumas are scratches $(82.2 \%)$, while the number of individuals with gashes accounts for only a few percentage points $(2.7 \%)$. Therefore, it is reasonable to consider that deep cuts were concentrated in Seiyokan.

Another feature of the Seiyokan cut marks is the location: they are distributed widely not only on cranial vaults but also on facial bones, while both the YCSB and YM crania do not show any cut marks on facial bones (Table 4).

\section{Age and sex}

Table 5 indicates the age and sex composition of the individuals with cut marks in Seiyokan, YCSB, and YM. The individuals with cut marks possibly exhibiting lethal cuts were mainly adults. We cannot detect a pronounced tendency in sexual difference due to the small number of specimens, but the high frequency of cranial traumas in adult males is consistent with most previous studies (e.g. Tung, 2007; Jimenez-Brobeil et al., 2009; Nagaoka et al., 2009).

\section{SEM observation for identification of cut marks}

We further examined the indeterminable case of cut marks found on one individual from a single grave (specimen

Table 4. Comparison of location of cut marks among three archaeological sites

\begin{tabular}{|c|c|c|c|c|c|c|c|}
\hline \multirow{2}{*}{ Archaeological sites ${ }^{\mathrm{a}}$} & \multicolumn{7}{|c|}{ Number and frequency (\%) of cut marks ${ }^{b}$} \\
\hline & ZYG & NAS & MAX & FRO & PAR & TEM & OCC \\
\hline \multirow[t]{2}{*}{ Seiyokan } & 1 & 2 & 1 & 2 & 12 & 3 & 4 \\
\hline & $(4.00)$ & $(8.00)$ & $(4.00)$ & $(8.00)$ & $(48.00)$ & $(12.00)$ & $(16.00)$ \\
\hline \multirow[t]{2}{*}{$\mathrm{YCSB}^{\mathrm{c}}$} & 0 & 0 & 0 & 3 & 11 & 0 & 2 \\
\hline & $(0.00)$ & $(0.00)$ & $(0.00)$ & $(18.75)$ & $(68.75)$ & $(0.00)$ & $(12.50)$ \\
\hline \multirow[t]{2}{*}{$Y^{d}$} & 0 & 0 & 0 & 7 & 8 & 0 & 1 \\
\hline & $(0.00)$ & $(0.00)$ & $(0.00)$ & $(43.75)$ & $(50.00)$ & $(0.00)$ & $(6.25)$ \\
\hline
\end{tabular}

${ }^{\text {a }}$ YCSB, Yuigahama Chusei Shudan Bochi; YM, Yuigahama-minami.

${ }^{\mathrm{b}}$ ZYG, zygomatic bone; NAS, nasal bone; MAX, maxilla; FRO, frontal bone; PAR, parietal bone; TEM, temporal bone; OCC, occipital bone. When the number of cut marks on each bone was recorded, a continuous cut mark on two bones or more was counted separately according to each bone. The frequency for each bone is in parentheses.

${ }^{\mathrm{c}}$ Nagaoka et al. (2009).

${ }^{\mathrm{d}}$ Hirata et al. $(2002,2004)$.

Table 5. Comparison of age and sex composition of individuals with cut marks among three archaeological sites

\begin{tabular}{|c|c|c|c|c|c|}
\hline \multirow{3}{*}{ Archaeological sites ${ }^{\mathrm{a}}$} & \multicolumn{5}{|c|}{ Number and frequency (\%) of individuals with cut marks ${ }^{\mathrm{b}}$} \\
\hline & \multirow{2}{*}{ Subadult } & \multicolumn{3}{|c|}{ Adult } & \multirow{2}{*}{ Unknown age } \\
\hline & & Male & Female & Unknown sex & \\
\hline Seiyokan & $\begin{array}{c}0 \\
(0.00)\end{array}$ & $\begin{array}{c}3 \\
(50.00)\end{array}$ & $\begin{array}{c}1 \\
(16.67)\end{array}$ & $\begin{array}{c}1 \\
(16.67)\end{array}$ & $\begin{array}{c}1 \\
(16.67)\end{array}$ \\
\hline $\mathrm{YCSB}^{\mathrm{c}}$ & $\begin{array}{c}1 \\
(12.50)\end{array}$ & $\begin{array}{c}3 \\
(37.50)\end{array}$ & $\begin{array}{c}1 \\
(12.50)\end{array}$ & $\begin{array}{c}0 \\
(0.00)\end{array}$ & $\begin{array}{c}3 \\
(37.50)\end{array}$ \\
\hline $\mathrm{YM}^{\mathrm{d}}$ & $\begin{array}{c}0 \\
(0.00)\end{array}$ & $\begin{array}{c}2 \\
(50.00)\end{array}$ & $\begin{array}{c}2 \\
(50.00)\end{array}$ & $\begin{array}{c}0 \\
(0.00)\end{array}$ & $\begin{array}{c}0 \\
(0.00)\end{array}$ \\
\hline
\end{tabular}

${ }^{a}$ YCSB, Yuigahama Chusei Shudan Bochi; YM, Yuigahama-minami.

$\mathrm{b}$ The frequency for each bone is in parentheses.

${ }^{\mathrm{c}}$ Nagaoka et al. (2009).

${ }^{\mathrm{d}}$ Hirata et al. (2002, 2004). 


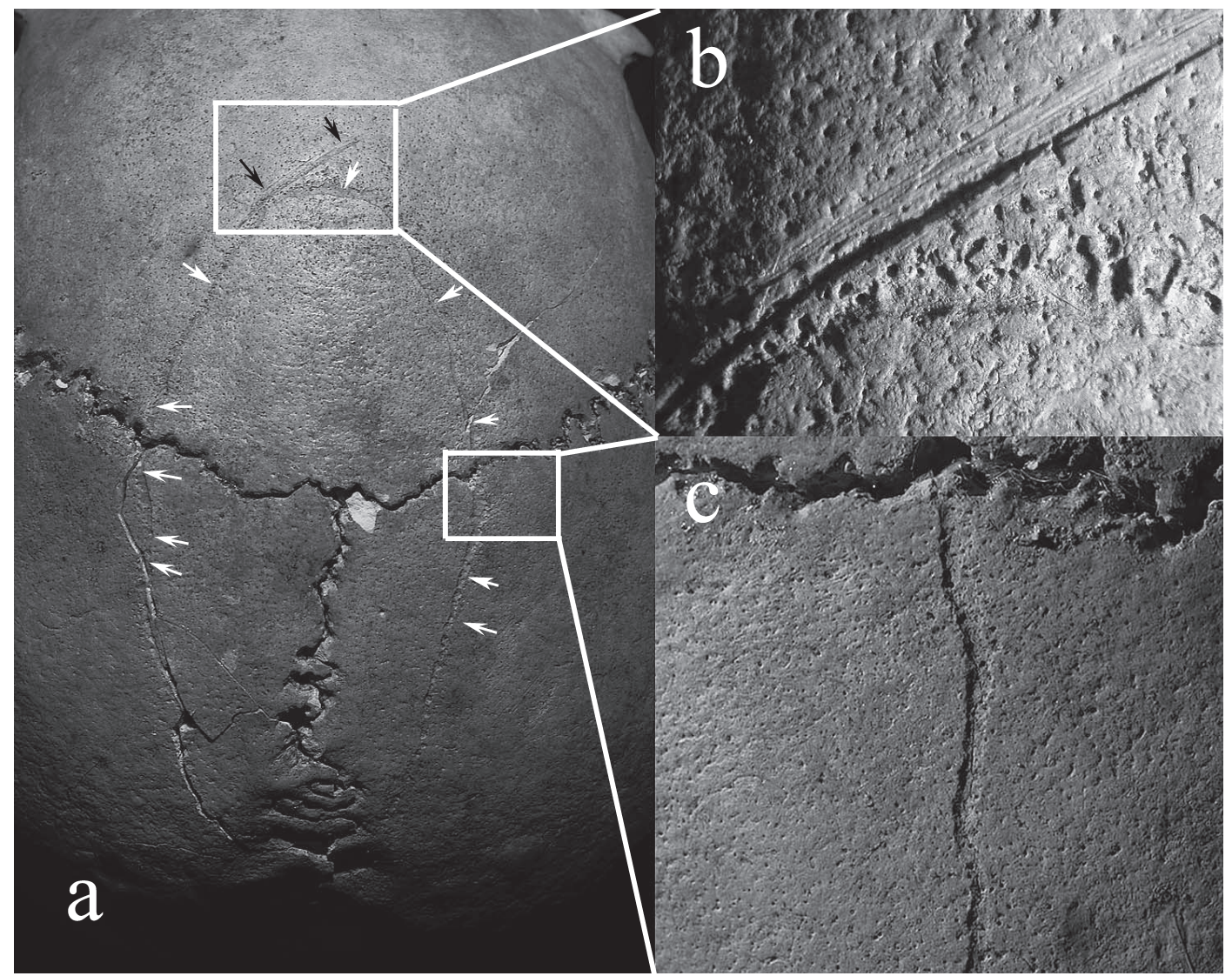

Figure 3. Superior view of cranium (specimen no. W-1). (a) A straight mark on the frontal bone (black arrows) and a circular depression surrounding the right and left parietal and frontal bones (white arrows). (b) Close-up view of the straight mark on the frontal bone. This is a straight mark on the middle of the frontal bone (24 mm long), running in a left anterior-right posterior direction. (c) Close-up view of the circular depression surrounding the right and left parietal and frontal bones.

no. W-1). The individual is a male, whose age at death was estimated to be 20-29 years. The case described here is an unusual combination of two traumas on the cranial vault (Figure 3).

The first is a straight wound on the middle of the frontal bone ( $24 \mathrm{~mm}$ long), running in a left anterior-right posterior direction (black arrows in Figure 3). Upon gross visual inspection, this exhibits a broad and shallow groove with a flat-bottomed apex in cross section and the presence of fine striations within the grooves. There is no sign of healing and no color difference between the groove walls and the original bone surfaces. In order to inspect the morphological traits in detail, a selected area of a groove (b in Figure 3) was magnified using a SEM (Figure 4). The SEM image reveals a flatbottomed cross section with an irregular and scalloped outline of the groove, which is not consistent with the diagnostic standards of cut marks defined by Shipman and her colleagues (Shipman, 1981; Shipman and Rose, 1983; Shipman et al., 1984). Cut marks made by a slicing motion usually produce a V-shaped cross section, but they do not remain in such an irregular and scalloped outline. In the present case, therefore, the possibility cannot be ruled out that the irregular and scalloped outline of the groove was produced by preparation damages after weathering or other taphonomic processes. Microscopic features sometimes provide insuffi- cient evidence of cut marks, because cut marks are often obscured and misdiagnosed due to natural or post-excavation processes (Shipman and Rose, 1983; Behrensmeyer et al., 1986; White and Toth, 1989). Behrensmeyer et al. (1986) suggested that taphonomic processes such as trampling can alter the features of pre-existing cut marks, eliminating the original sharpness and internal striations. With the current data available, it cannot plausibly be argued that Figure 4 represents the morphological features of cut marks.

The second mark to be examined in detail is a circular depression running around the right and left parietal bones and the frontal bone (white arrows in Figure 3). This mark exhibits a round and shallow groove and no color difference between modified and original bone surfaces (c in Figure 3). Under microscopic magnification, the depression shows a groove with a U-shaped apex in cross section and round edges (Figure 5). This is not consistent with the diagnostic standards of cut marks and it is necessary to consider another cause of bone modification which creates shallow grooves. Potential biostratinomic factors consist of root etching and gnawing by animals. The roots of many plants excrete humic acid, and shallow grooves on bone surfaces are often interpreted as the result of etching by this acid (Behrensmeyer, 1978; Lyman, 1994). However, the grooves associated with root etching usually show a dendritic shape 


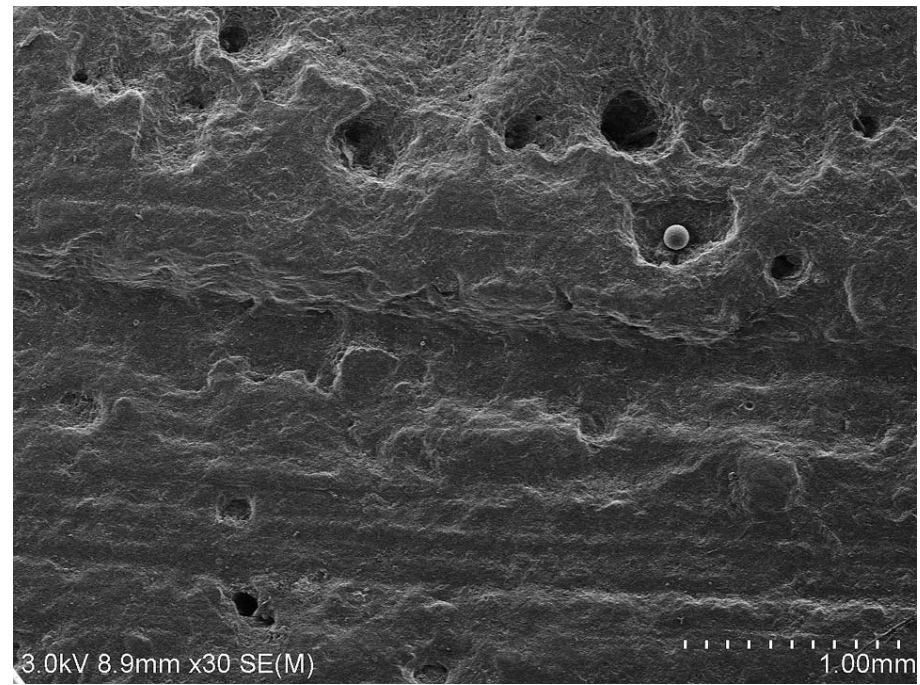

Figure 4. Microscopic magnification of $\mathrm{b}$ of Figure 3 (specimen no. W-1).

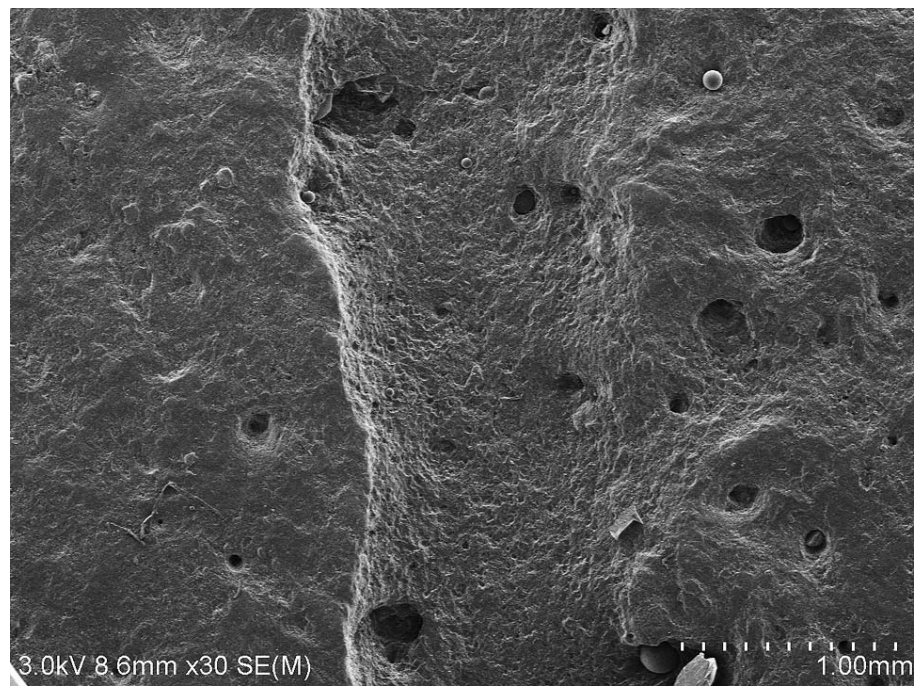

Figure 5. Microscopic magnification of $\mathrm{c}$ of Figure 3 (specimen no. W-1).

that reflects the growing pattern of the roots. The circular depression of the cranial specimen does not fit this pattern.

Gnawing by various animals is also known to result in shallow grooves on the bone surface. The U-shaped cross section of the circular depression on the crania resembles the tooth impression of carnivores. Nevertheless mammals seldom draw a circular single line on bone surface with their teeth. Additionally the tooth pits and jagged bone edges that tend to be associated with mammals' gnawing behavior were not observed on the specimen. Insects and microscopic organisms can also modify the bone surface. Behrensmeyer (1978) reported that the larvae of the moth Tinea deperdella caused shallow grooving on horn cores of a Grant's gazelle. Watson and Abbey (1986) also found that Australian termites created scratches on the bone surface. However, these grooves are more or less short and linear, and these bone grooving insects are not known in Japan. In short any assum- able non-human related postmortem process may not be responsible for the current mark.

The most difficult and important question we have to ask here is how the circular depression was produced. Fortunately, we found some hints in an interesting case report of healed cut marks. Such cases have been detected in Native American crania, which Hamperl (1967) has described as possible evidence of scalping. Scalping is anatomically defined as "incising the skin over the skull down to the galea and the periosteum with a sharp object in a circular manner" (Hamperl, 1967: 630). If scalping was done on living persons and the individuals were able survive for some time thereafter, a healing reaction would be expected on the bone surfaces (Hamperl, 1967). Hamperl (1967: 631-634) stated:

"The bone, deprived of its periosteum, will gradually exsiccate in its superficial portions and become necrotic, an inflammatory granulation tissue then separates it from 
deeper layers of living bone through demarcation. A new spongy bone tissue is formed by the remaining inner bone layers, which is eventually covered by regenerating epidermis and the wound closes. ... One would visualize a circular incision being carried out on the skull and leaving an infected wound, but without removing the skin with the periosteum as done in scalping."

That is to say, a sequence of changes after mutilation led to a groove-like bone destruction circulating around the cranial vault. Both the cases depicted in this study and Hamperl (1967) seem alike in terms of the morphological features. Whereas the diagnosis of Figure 5 is not straightforward, it may be assumed that the circular depression was produced in a series of healing reactions. A morphological comparison between the present and preceding studies is the best and only method for interpreting the circular depression. An experimental study using living humans or non-human subjects to determine whether the circular depression on the cranium is healed or not is not possible for ethical reasons.

Although there is no direct historical evidence of scalping in medieval Japan, trophy-taking, usually involving cutting of human body parts, was a widespread practice among the warriors. The samurai removed the heads of their enemies as proof of achievement according to the moral code of Bushido and displayed the decapitated heads to show how enemies were punished. The historical records of medieval Japan have suggested that the removal of soft tissues was actually practiced on living persons for criminal punishment and these criminals sometimes had body parts removed as a deliberate mutilation, resulting in physical disfigurement (Katsumata, 1983). Osteological evidence has also confirmed the presence of scratches in the archeological sites of YCSB and Zaimokuza, which were possibly made in removing soft tissues from crania (Nagaoka et al., 2009; Suzuki, 1956). Hence, healing after mutilation is a possible explanation for the circular depression, and we cannot find any other plausible explanation.

\section{Conclusion}

This study examined human skeletons from Seiyokan, a medieval burial site in Kamakura, and documented cut marks on crania made by an edged weapon. The results demonstrate that the cranial traumas have morphological features consistent with human-induced cut marks. Whereas the traumas found on the Seiyokan samples are distinguishable in terms of cut mark morphology and distribution from those found in other archeological sites, sharp-force traumas have been commonly observed not only in YCSB, YM, and Zaimokuzam, but also in Seiyokan. Several earlier studies have shown that human skeletons from medieval Japan exhibit traumatic injuries related to violence, such as gashes, decapitations, blows, stabbing, and scratches (Suzuki, 1956; Morimoto, 1987; Morimoto and Hirata, 1992; Hirata et al., 2002, 2004; Hirata and Nagaoka, 2005; Nagaoka et al., 2009). The characteristics of cut marks found on the Seiyokan samples strongly suggest the prevalence of violence in the medieval period. The presence of cut marks in females further implies that the victims might have included nonwarrior classes. The osteological evidence is in accord with the historical characteristics of the period - that a militarily organized society was founded by force and that the rise to political power of the warrior class and the establishment of a military government resulted in continuous disturbances, armed conflicts, and violent death.

Another interesting finding here is the groove-like depression circulating around a male cranium (white arrows in Figure 3). Macroscopic and microscopic approaches are of limited use in identifying anthropogenic cut marks, in particular if the lesions have healed (Jimenez-Brobeil et al., 2009). Although the diagnosis of Figure 5 is not straightforward, it may be assumed that the circular depression was produced by a series of healing reactions. If this is the case, the presence of this unusual trauma on the Seiyokan cranium implies a wide variability of cut marks and shows a contrast with other archeological sites (YCSB, YM, and Zaimokuza), which have no evidence for such a trauma.

These findings help us to refine our understanding of the variability of weapon-related traumas in the medieval period in Japan, and to reconstruct the death situations of past human populations.

\section{Acknowledgments}

This study is supported in part by a Grant-in-aid for Young Scientists (B) (No. 20770197) from the Ministry of Education, Culture, Sports, Science and Technology of Japan.

\section{References}

Andrushko V.A., Latham K.A.S., Grady D.B., Pastron A.G., and Walker P.L. (2005) Bioarchaeological evidence for trophy taking in prehistoric central California. American Journal of Physical Anthropology, 127: 375-384.

Behrensmeyer A.K. (1978) Taphonomic and ecologic information from bone weathering. Paleobiology, 4: 150-152.

Behrensmeyer A.K., Gordon K.D., and Yanagi G.T. (1986) Trampling as a cause of bone surface damage and pseudocutmarks. Nature, 319: 768-771.

Binford L.R. (1981) Bones Ancient Men and Modern Myths. Academic Press, NY.

Boylston A. (2000) Evidence for weapon-related trauma in British archaeological samples. In: Cox M. and Mays S. (eds.), Human Osteology in Archaeology and Forensic Science. Cambridge University Press, Cambridge, pp. 357-380.

Bruzek J. (2002) A method for visual determination of sex using the human hip bone. American Journal of Physical Anthropology, 117: 157-168.

Buckberry J.L. and Chamberlain A.T. (2002) Age estimation from the auricular surface of the ilium: a revised method. American Journal of Physical Anthropology, 119: 231-239.

Buzon R. and Richman R. (2007) Traumatic injuries and imperialism: the effects of Egyptian colonial strategies at Tombos in Upper Nubia. American Journal of Physical Anthropology, 133: 783-791.

Cook J. (1986) The application of scanning electron microscopy to taphonomic and archaeological problems. British Archaeological Reports International Series, 296: 143-163.

Finucane B.C. (2008) Trophy heads from Nawinpukio, Peru: physical and chemical analysis of Huarpa-era modified human remains. American Journal of Physical Anthropology, 135: 75-84.

Greenfield H.J. (1999) The origins of metallurgy: distinguishing stone from metal cut-marks on bones from archaeological sites. Journal of Archaeological Science, 26: 797-808. 
Hamperl H. (1967) The osteological consequence of scalping. In: Brothwell D. and Sandison A.T. (eds.), Disease in Antiquity: A Survey of Disease, Injuries and Surgery of Early Populations. Charles C. Thomas, Springfield, IL, pp. 630-634.

Hirata K. and Nagaoka T. (2005) Shutsudo jinkotsu no chosa. In: Koyama H. (ed.), Yuigahama chusei shudan bochi iseki. Tamagawa bunkazai kenkyusho, Kanagawa, pp. 205-213 (in Japanese).

Hirata K., Oku C., Hoshino K., Tomo S., and Takahashi S. (2002) Yuigahama-minami iseki no tantai maiso iko jinkotsu ni tsuite. In: Yuigahama-minami iseki hakkutsu chosa dan (ed.), Yuigahama-minami iseki 2. Yuigahama-minami iseki hakkutsu chosa dan, Kamakura, 1-240 (in Japanese).

Hirata K., Nagaoka T., and Hoshino K. (2004) Analysis of injuries by swords in medieval Japanese skeletons from Yuigahama, Kamakura. Anthropological Science (Japanese Series), 112: 19-26 (in Japanese with English summary).

Jimenez-Brobeil S.A., du Souich P.h., and Al Oumaoui I. (2009) Possible relationship of cranial traumatic injuries with violence in the south-east Iberian Peninsula from the Neolithic to the Bronze Age. American Journal of Physical Anthropology, 140: 465-475.

Katsumata S. (1983) Mimi wo kiri hana wo sogu. In: Amino Y., Ishii S., Kasamatsu H., and Katsumata S. (eds.), Chusei no tsumi to batsu. University of Tokyo Press, Tokyo, pp. 27-42 (in Japanese).

Larsen C.S. (1997) Injury and Violent death. Bioarchaeology. Interpreting Behaviour from the Human Skeleton. Cambridge University Press, Cambridge, pp. 109-160.

Lewis J.E. (2008) Identifying sword marks on bone: criteria for distinguishing between cut marks made by different classes of bladed weapon. Journal of Archaeological Science, 35: 20012008.

Lovejoy C.O., Meindl R.S., Pryzbeck T.R., and Mensforth R.P. (1985) Chronological metamorphosis of the auricular surface of the illium: a new method of determining adult age at death. American Journal of Physical Anthropology, 68: 15-28.

Lyman R.L. (1994) Vertebrate Taphonomy. Cambridge University Press, Cambridge.

Morimoto I. (1987) Note on the technique of decapitation in medieval Japan. Journal of Anthropological Society of Nippon, 95: $477-486$.

Morimoto I. and Hirata K. (1992) A decapitated human skull from medieval Kamakura. Anthropological Science, 100: 349-358.

Morimoto I., Takahashi Y., and Hirata K. (1984) Jinkotu no shoken. In: Kamakura City Board of Education (ed.), Kamakurashi chusei shudan bochi (tokushu yogo rojin homu kamakura seiyokan kensetsu yoteichi) hakkutsu chosa hokokusho, Kamakura City Board of Education, Kamakura, pp. 8-11 (in Japanese).

Murphy E., Gokhman I., Chistov Y., and Barkova L. (2002) Prehistoric old world scalping: new cases from the cemetery of Aymyrlyg, South Siberia. American Journal of Archaeology, 106: $1-10$

Nagaoka T., Shizushima A., Sawada J., Tomo S., Hoshino K., Sato H., and Hirata K. (2008) Sex determination using mastoid process measurements: standards for Japanese human skeletons of the medieval and early modern periods. Anthropological Science, 116: 105-113.

Nagaoka T., Uzawa K., and Hirata K. (2009) Weapon-related traumas of human skeletons from Yuigahama Chusei Shudan Bochi, Japan. Anatomical Science International, 84: 170-181.

Okada M. (1961) On the age-related changes of cranial sutures in Kanto Japanese. Jikei Medical Journal, 77: 112-167 (in Japanese)

Phenice T.W. (1969) A newly developed visual method of sexing the os pubis. American Journal of Physical Anthropology, 30: 297-301.

R Development Core Team (2005) R: A language and environment for statistical computing. R Foundation for Statistical Computing. Vienna, Austria. http://www.R-project.org

Rose J.J. (1983) A replication technique for scanning electron microscopy: application for anthropologists. American Journal of Physical Anthropology, 62: 255-261.

Shipman P. (1981) Applications of scanning electron microscopy to taphonomic problems. Annals of the New York Academy of Science, 376: 357-385.

Shipman P. and Rose J.J. (1983) Evidence of butchery and hominid activities at Trralba and Ambrona; an evaluation using microscopic techniques. Journal of Archaeological Science, 10: 465-474.

Shipman P., Fisher D.C., and Rose J.J. (1984) Mastodon butchery: microscopic evidence of carcass processing and bone tool use. Paleobiology, 103: 358-365.

Suzuki H. (1956) Jinkotsu no sonsho. In: Anthropological Society of Nippon (ed.), Medieval Japanese skeletons from the burial site at Zaimokuza, Kamakura city. Iwanami shoten, Tokyo, pp. 30-57 (in Japanese with English summary).

Suzuki H. (1989) The head burial sites in the Numazu city and the skull of the medieval Japanese. Journal of Anthropological Society of Nippon, 97: 23-37 (in Japanese with English summary).

Tashiro I. and Tamabayashi Y. (1984) Matome. In: Kamakura City Board of Education (ed.), Kamakurashi chusei shudan bochi (tokushu yogo rojin homu kamakura seiyokan kensetsu yoteichi) hakkutsu chosa hokokusho, Kamakura City Board of Education, Kamakura, pp. 12 (in Japanese).

Todd T.W. (1920) Age changes in the pubic bone: I. The white male pubis. American Journal of Physical Anthropology, 3: 285-334.

Todd T.W. (1921) Age changes in the pubic bone: II. the pubis of the male Negro-White hybrid; III. The pubis of the White female; IV. The pubis of the female Negro-White hybrid. American Journal of Physical Anthropology, 4: 1-70.

Tung T. (2007) Trauma and violence in the Wari Empire of the Peruvian Andes: warfare, raids, and ritual fights. American Journal of Physical Anthropology, 133: 941-956.

Ubelaker D.H. (1989) Human skeletal remains: excavation, analysis, interpretation, 2nd edition. Aldine, Chicago, IL.

Wakebe T. (1990) A morphological study of crania of infants and children in the Japanese. Nagasaki Medical Journal, 65: 805824 (in Japanese with English title).

Walker P.L. (2001) A bioarchaeological perspectives on the history of violence. Annual Review of Anthropology, 30: 573596.

Walker P.L. and Long J.C. (1977) An experimental study of the morphological characteristics of tool marks. American Antiquity, 42: 605-616.

Watson P.J. and Abbey H.M (1986) The effects of termites (Isoptera) on bone: some archaeological implications. Sociobiology, 11: 245-254.

White T.D. (1992) Prehistoric cannibalism at Mancos 5MTUMR2346. Princeton University Press, Princeton, NJ.

White T.D. and Folkens P.A. (2000) Human Osteology, 2nd edn. Academic Press, London.

White T.D. and Toth N. (1989) Engis: preparation damage, not ancient cutmarks. American Journal of Physical Anthropology, 78: 361-367.

Williamson M.A., Johnston C.A., Symes A.S., and Schultz J.J. (2003) Interpersonal violence between 18th century Native Americans and Europeans in Ohio. American Journal of Physical Anthropology, 122: 113-122. 


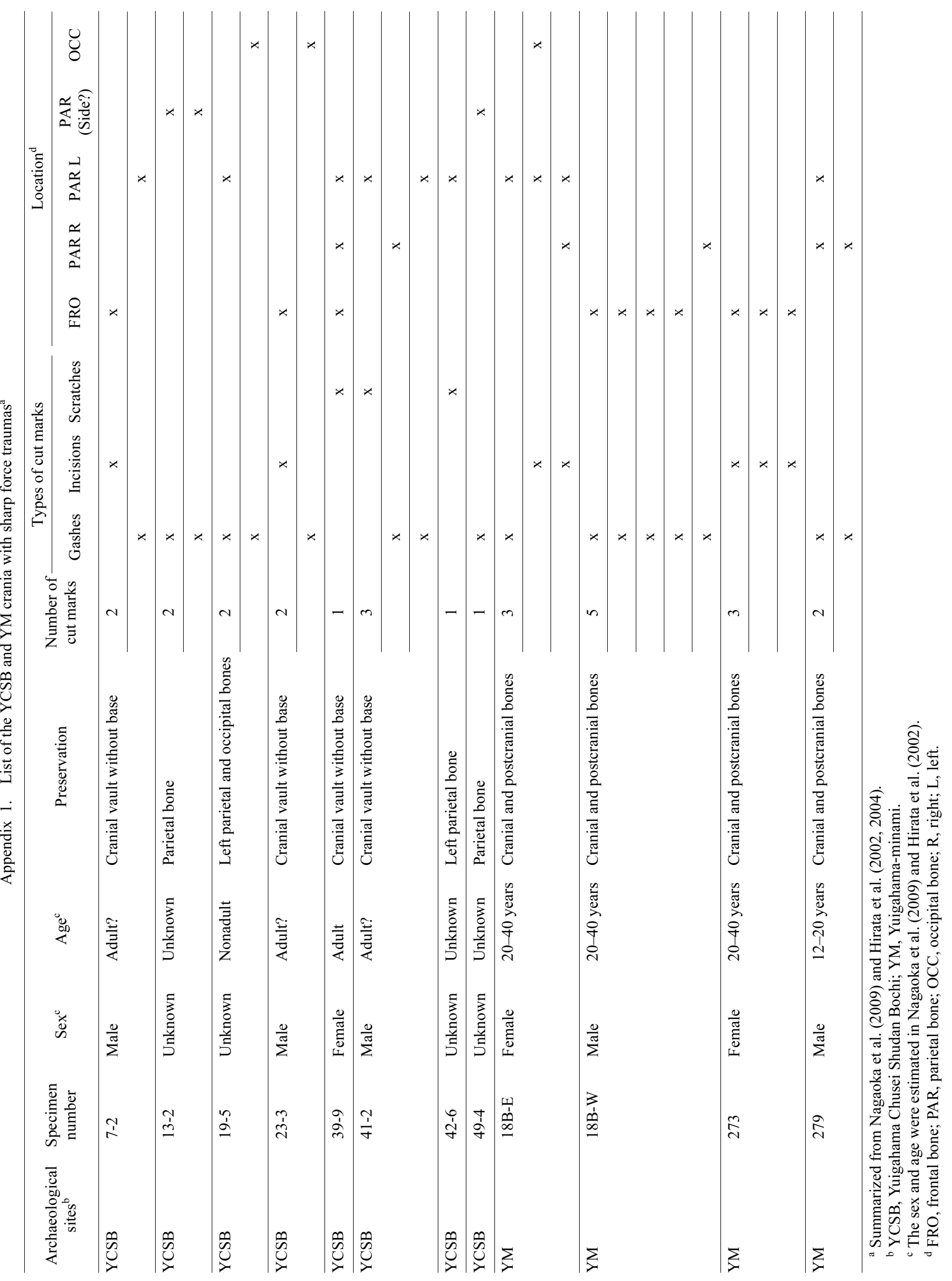

